\title{
A Multiband Slot Antenna loaded with Stubs for WLAN/WiMAX/Satellite TV Applications
}

\author{
Imran Khan ${ }^{1}$, Tanweer Ali ${ }^{2 *}$, Geetha D. Devanagavi ${ }^{1}$, Sudhindra K R ${ }^{3}$, Rajashekhar C. Biradar ${ }^{1}$ \\ ${ }^{1}$ School of Electronics and Communication Engineering, REVA University, Bangalore, India \\ ${ }^{2}$ Department of E\&C, Manipal Institute of Technology, MAHE, Manipal, India \\ ${ }^{3}$ BMSCE, Department of Electronics and Communication Engineering, Bangalore, India \\ *corresponding author, E-mail: tanweer.ali@manipal.edu
}

\begin{abstract}
A compact planar multiband antenna operating at 2.65 (lower WiMAX)/5.20 (WLAN)/6.75/7.30 GHz (Satellite TV) is presented. The antenna consists of circular radiator in which a rectangular slot is etched out. Also, the circular radiator is loaded with a rectangular and two hook-shaped stubs to achieve multiband operations. The impedance matching at these bands is achieved by using two small square stubs placed inside the hook-shaped stubs. The antenna has an electrical dimension of $0.17 \lambda_{1} \times 0.17 \lambda_{1} \times$ $0.01 \lambda_{1}$ at the lower frequency of $2.65 \mathrm{GHz}$. The antenna has $\mathrm{S}_{11}<-10 \mathrm{~dB}$ bandwidth of $3 \%(2.6-2.68 \mathrm{GHz}), 2.3 \%(5.12-$ $5.24 \mathrm{GHz}), \quad 1.2 \% \quad(6.68-6.76 \mathrm{GHz})$ and $1.37 \% \quad(7.26-$ $7.36 \mathrm{GHz})$ in simulation and about $6.25 \%(2.48-2.64 \mathrm{GHz})$, $2.24 \%(5.3-5.42 \mathrm{GHz}), 1.15 \%(6.92-7.00 \mathrm{GHz})$ and $1.1 \%$ $(8.04-8.12 \mathrm{GHz})$ under measurement. The entire simulation analysis of the antenna is carried out using HFSS v.13.0.
\end{abstract}

Key words- compact; stubs; radiator; slot

\section{Introduction}

The advancement in the field of multifunction devices concentrated more in the recent years. It is essential to design and deploy the antenna effectively for the reason that it is the most critical part of wireless system. The technology has experienced the sudden development in the evergrowing field of communication inventions such as from pagers to mobile phones, wire lines to wireless approaches [1]. These advancements may take the ultimate place of solace for human existences. The principal hand over in the advancement of patch antennas was the revelation of their multiband nature. The different kinds of antenna utilized to accomplish remote applications are monopole, dipole, and microstrip patch antennas [2]. Besides, to attain the wireless quality and broad application coverage on single device multiband antennas play vital roles. Aside from covering these numerous applications, multiband antennas likewise sob in the field of size, cost and high information rate highlights. They can be effectively coordinated with control and switching circuits.

Literature suggests a number of techniques for obtaining multiband antenna configuration such as slots [3-6] fractals
[7], defected ground structure [8], metamaterials [9-13], multiresonators [14], and reactive loads [15]. Achieving a compact size of antenna is very efficient and is done by means of altering the near field boundary conditions. There are few devices such as communication handsets which incorporates limited space for an antenna. In addition to this to operate on larger number of operation bands corresponding to the diversity of the application embedded requires the radiation elements to resonate simultaneously.

In this paper a compact multiband planar antenna loaded with rectangular and hook-shaped stub is presented. Multiband operation in the proposed configuration is achieved by two hook-shaped and a rectangular stub placed on the radiator. The partial ground plane is utilized to match the impedance at the obtained band along with the small square stub placed inside the hook-shaped stub. Parametric investigations are carried out to finalize the dimensions of antenna by analyzing its operational behavior at the respective dimensions. The entire operation of the antenna is carried out on HFSS v.13.0 simulator using FEM method.

\section{Antenna Design}

The main objective of this research is to obtain a compact multiband antenna with good radiation characteristics. To obtain this objective, the proposed configuration is illustrated in Figure 1. The antenna is implemented on a single layer dielectric substrate. In this study we consider a low cost, readily available FR4 substrate with $\delta=0.02, \mathrm{~h}=1.6 \mathrm{~mm}$ and $\varepsilon_{r}=4.4$. The proposed structure consists of a circular radiator with embedded rectangular slot, two hook-shape stubs and a rectangular stub in conjunction with the feed line. In the hook-shaped at the downside square stub $\left(\mathrm{W}_{4} \times \mathrm{WW}_{4}\right)$ is kept to achieve better impedance matching at the operating bands. A rectangular slot $\left(\mathrm{WxG}_{1}\right)$ is etched out in the ground plane to achieve an overall impedance matching of the antenna. The antenna is energized by a microstrip feed line $\left(\mathrm{W}_{\mathrm{p}} \times \mathrm{L}_{3}\right)$. 


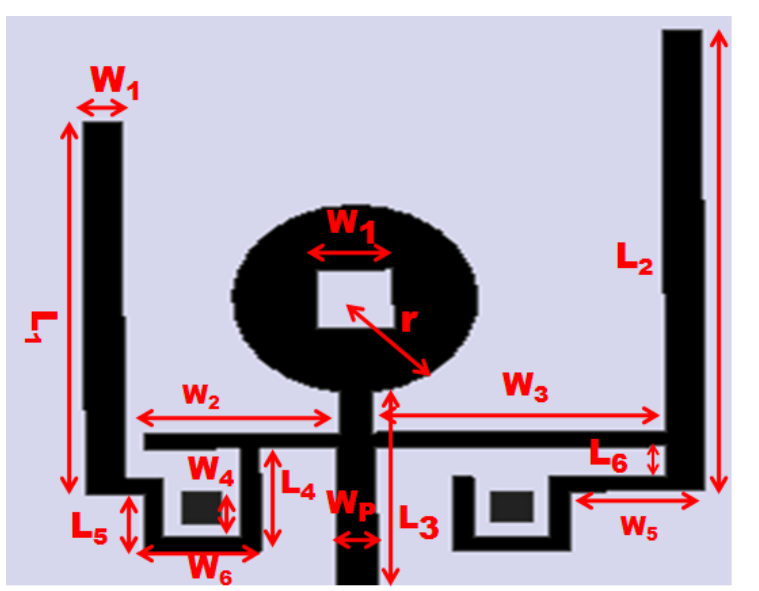

(a)

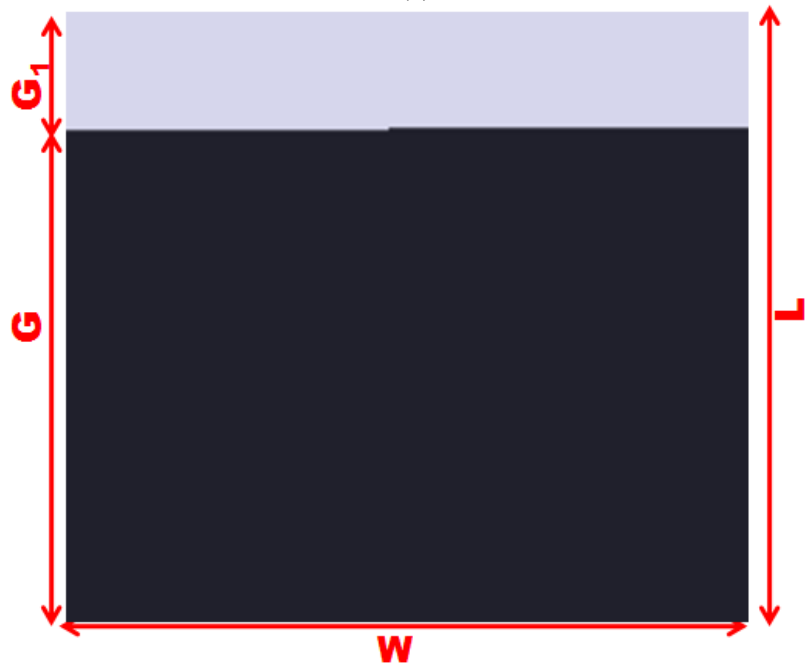

(b)

Figure 1. Structure of the proposed configuration (a) front part (b) back part.

The various design evolution steps of the proposed structure is presented in Figure 2 and their $S_{11}$ results are demonstrated in Figure 3. In these design evolution steps the effect of adding various stubs to the radiator is studied. One thing to note here is that in all these design evolution steps the ground plane is kept same (i.e. partial ground plane as shown in Figure1). In the first step, a circular patch antenna with a rectangular slot is designed as demonstrated in configuration "Design 1" of Figure 2. It can be noticed that in Figure 3, that this antenna does not show any resonance. To incorporate the useful operating band, a rectangular stub is included in conjunction with the feed line as demonstrated in configuration "Design 2" of Figure 3. The introduction of this stub modifies the surface current which tends the antenna to operate at 4.7 and $5.95 \mathrm{GHz}$ (Figure 3). However, only dual band operation is achieved from this configuration. So, to increase the number of operating band two hook-shaped stubs are included in conjunction with rectangular stub of "Design 2" as demonstrated in configuration "Design 3" of Figure 2. The introduction of these hook-shaped stubs further perturbs the surface current distribution which tends to increase the total current length path, thus making "Design 3" to operate at 2.65, 5.20, 6.75 and $7.30 \mathrm{GHz}$ respectively. But the problem associated with "Design 3" is that the $\mathrm{S}_{11}$ value at 2.65 and $6.75 \mathrm{GHz}$ is close to $-10 \mathrm{~dB}$, which may go above $-10 \mathrm{~dB}$ when the antenna is fabricated. Thus to avoid this circumstance, we introduce another square shaped stub placed inside the hook-shaped stub as illustrated in configuration "Design 4" of Figure 2. The inclusion of this square stubs improves the impedance match at 2.65 and $6.75 \mathrm{GHz}$, as illustrated in Figure 3. Finally by using this configuration (i.e. "Design 4") the antenna operates at 2.65 $\mathrm{GHz}$ (lower WiMAX), 5.20 GHz (WLAN), 6.75 and 7.30 $\mathrm{GHz}$ (Satellite TV) with good impedance matching, as demonstrated in Figure 3. Thus from the proposed design the aforementioned objective of achieving multiband nature from the antenna is successfully achieved. Moreover it can be noted that the antenna has dimension of only $20 \times 20 \times$ $1.6 \mathrm{~mm}^{3}$, thus, making it easier to integrate with various wireless devices. The final design dimension of the antenna is given in Table 1.

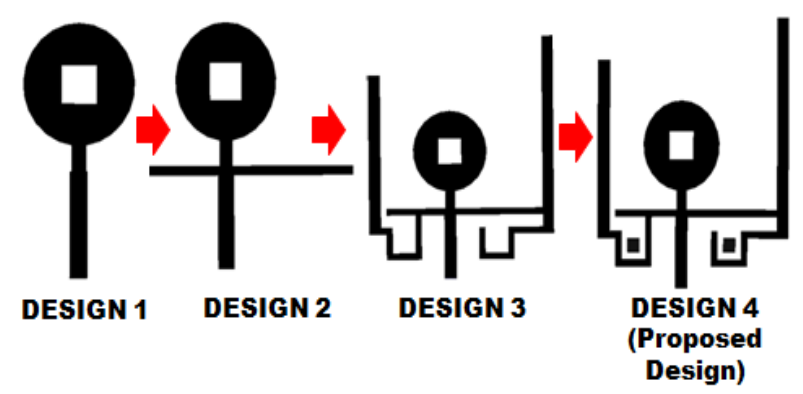

Figure 2. Design evolution steps of the proposed structure.

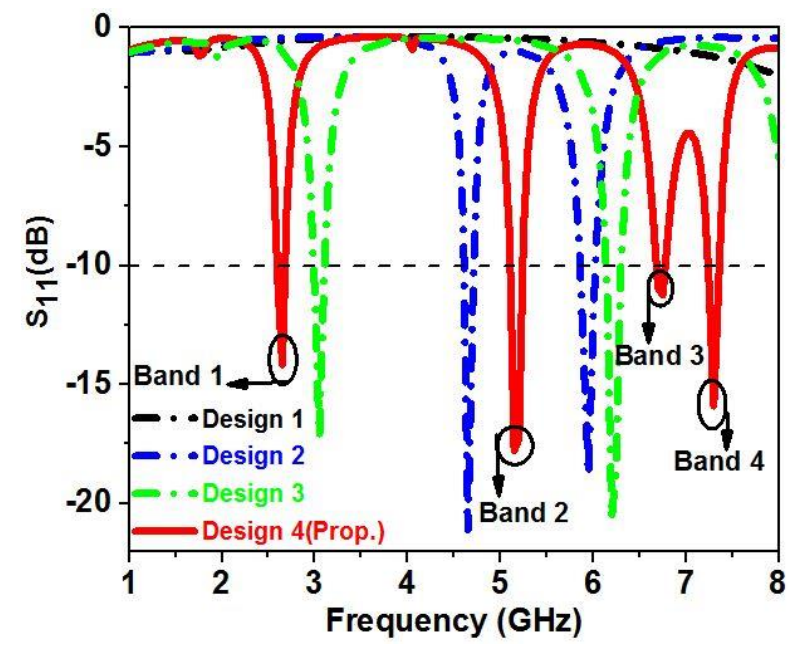

Figure 3. Various design evolution $\mathrm{S}_{11}$ results

Table 1: Antenna Dimensions.

\begin{tabular}{cc}
\hline Parameter & Dimensions $(\mathrm{mm})$ \\
\hline $\mathrm{G}$ & 16 \\
$\mathrm{G}_{1}$ & 4 \\
$\mathrm{r}$ & 3.1 \\
$\mathrm{~W}$ & 20 \\
$\mathrm{~W}_{\mathrm{p}}$ & 1 \\
$\mathrm{~W}_{1}$ & 1 \\
$\mathrm{~W}_{2}$ & 5 \\
$\mathrm{~W}_{3}$ & 7.6
\end{tabular}




\begin{tabular}{cc}
$\mathrm{W}_{4}$ & 1 \\
$\mathrm{~W}_{5}$ & 3 \\
$\mathrm{~W}_{6}$ & 3 \\
$\mathrm{~L}$ & 20 \\
$\mathrm{~L}_{1}$ & 12.5 \\
$\mathrm{~L}_{2}$ & 15.5 \\
$\mathrm{~L}_{3}$ & 6.8 \\
$\mathrm{~L}_{4}$ & 3.5 \\
$\mathrm{~L}_{5}$ & 2 \\
$\mathrm{~L}_{6}$ & 1 \\
\hline
\end{tabular}

\section{Parametric Analysis}

To investigate the effect of various design dimensions on antenna performance its parametric analysis is carried out and is demonstrated in Figure 4. These studies are done by varying one parameter at a time while keeping other parameters constant.

Firstly, the effect of ground plane on antenna impedance match is studied as demonstrated in Figure 4(a). The study is done by varying the length of ground plane from 15 to $17 \mathrm{~mm}$. At $\mathrm{G}=15 \mathrm{~mm}$ the impedance match at the third band is poor (i.e. as $S_{11}$ shifts above $-10 \mathrm{~dB}$ line). At $\mathrm{G}=17 \mathrm{~mm}$ the impedance matching at first and third resonance is poor (since $\mathrm{S}_{11}$ is very close to $-10 \mathrm{~dB}$ ). The best impedance matching for all the four band operating simultaneously is achieved at $\mathrm{G}=16 \mathrm{~mm}$.

In the second step, the analysis of width of left hand side hook-shaped stub is carried out. This is because this width affects the third resonant drastically. It can be noticed from Figure 4(b) that the best performance is achieved when $\mathrm{W}_{1}=2 \mathrm{~mm}$.

Similarly to first and second steps the variation of length of both the hook-shaped stubs $\left(\mathrm{L}_{1}\right.$ and $\left.\mathrm{L}_{2}\right)$ is carried and is presented in Figure 4(c) and (d) respectively. As it can be noticed that the best performance of the antenna is achieved at $\mathrm{L}_{1}=12.5 \mathrm{~mm}$ and $\mathrm{L}_{2}=15.5 \mathrm{~mm}$.

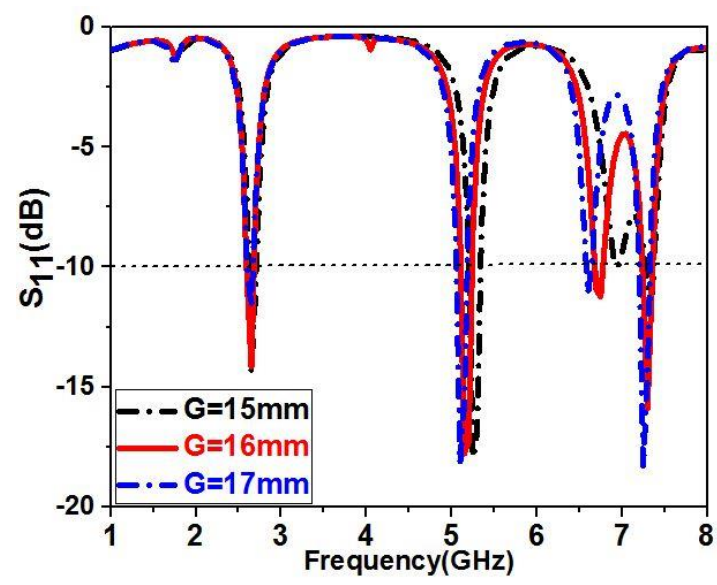

(a)

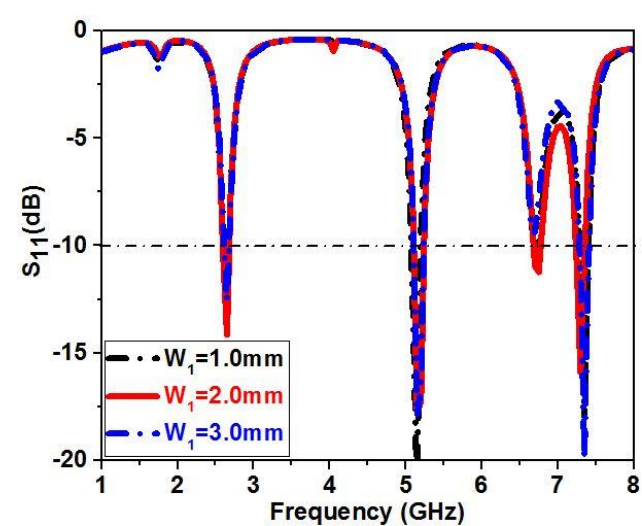

(b)

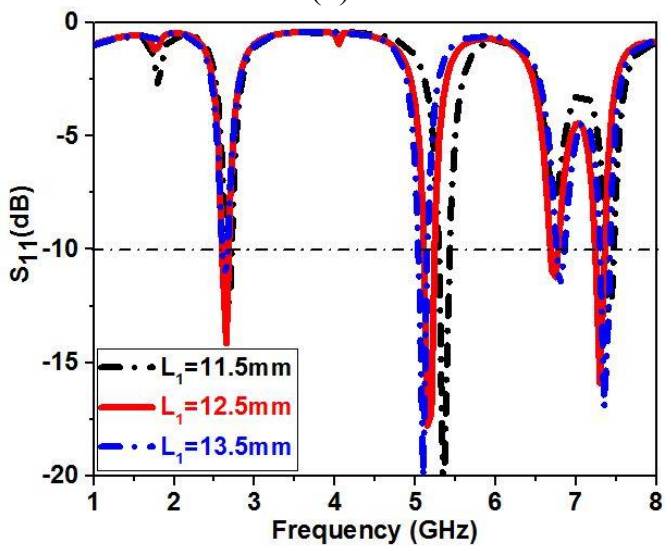

(c)

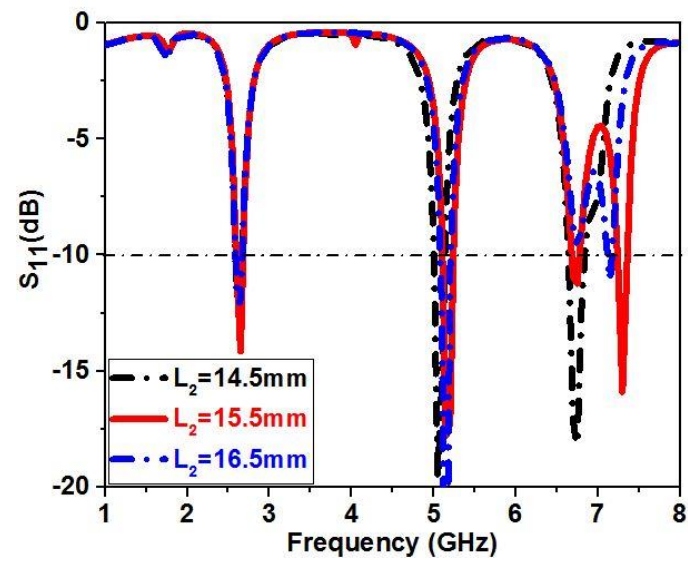

(d)

Figure 4. Parametric study of (a) Ground plane (G), (b) Width of left hand side hook-shaped stub $\left(\mathrm{W}_{1}\right)$, (c) Length of left side hookshaped stub $\left(\mathrm{L}_{1}\right)$ and $(\mathrm{d})$ Length of right hook-shaped stub $\left(\mathrm{L}_{2}\right)$

Furthermore, the phenomenon of resonance of the proposed configuration is studied by current distribution as presented in Figure 5. It can be noticed that for each resonance the antenna has a corresponding resonant path. 


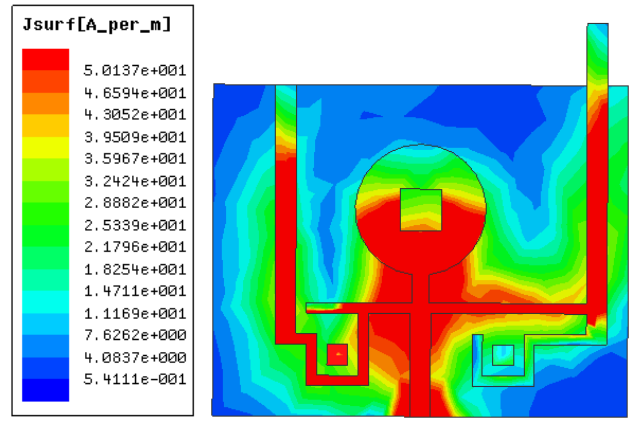

(a)

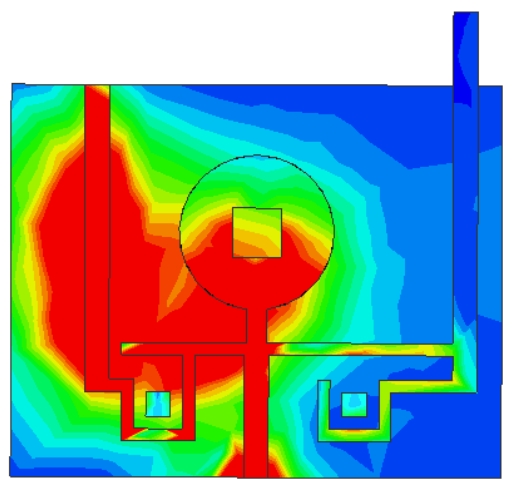

(b)

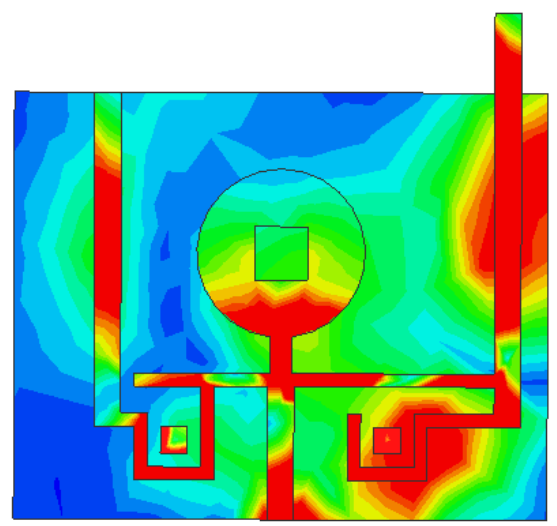

(c)

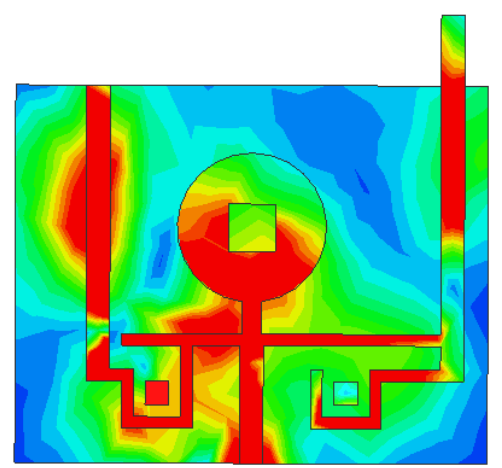

(d)

Figure 5. Current distribution at (a) $2.65 \mathrm{GHz}$, (b) $5.20 \mathrm{GHz}$, (c) $6.75 \mathrm{GHz}$ and (d) $7.30 \mathrm{GHz}$

\section{Results}

The proposed configuration is simulated on HFSS v.13.0 simulator using FEM method. The antenna is printed on FR4 substrate with $\delta=0.02, \mathrm{~h}=1.6 \mathrm{~mm}$ and $\varepsilon_{r}=4.4$. The antenna has a compact volume of only $640 \mathrm{~mm}^{3}(20 \times 20 \times$ $\left.1.6 \mathrm{~mm}^{3}\right)$. The fabricated model of the antenna is depicted in Figure 6.

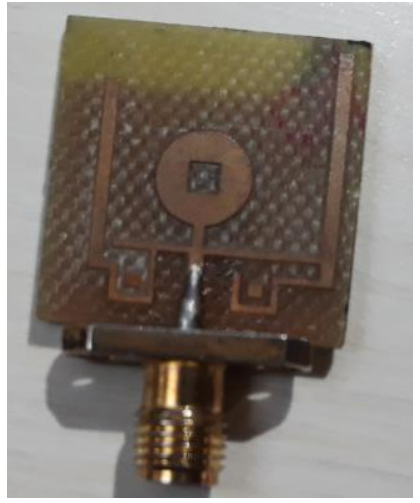

(a)

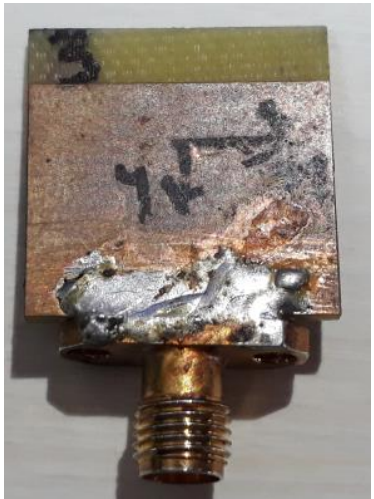

(b)
Figure 6. Fabricated model of the proposed antenna (a) front part (b) back part

The simulated $\mathrm{S}_{11}$ result of the antenna obtained from HFSS is depicted in Figure 7 and the measured result obtained form VNA is depicted in Figure 8. The antenna has $\mathrm{S}_{11}<-10$ $\mathrm{dB}$ bandwidth of 3\% (2.6-2.68 GHz), 2.3\% (5.12-5.24 $\mathrm{GHz}), 1.2 \%(6.68-6.76 \mathrm{GHz})$ and $1.37 \%(7.26-7.36 \mathrm{GHz})$ centered at $2.65 \mathrm{GHz}$ (lower WiMAX), 5.20GHz (WLAN), $6.75 \& 7.30 \mathrm{GHz}$ (Satellite TV) in simulation. Under measurement, the antenna has $\mathrm{S}_{11}<-10 \mathrm{~dB}$ bandwidth of about $6.25 \%(2.48-2.64 \mathrm{GHz}), 2.24 \% \quad(5.3-5.42 \mathrm{GHz})$, $1.15 \%(6.92-7.0 \mathrm{GHz})$ and $1.1 \%(8.04-8.12 \mathrm{GHz})$ centered at $2.56,5.39,6.97$ and $8.08 \mathrm{GHz}$, respectively. The simulated result complies with measured result slight variations may be due to the photolithographic etching process, loss incurred due to cable and during soldering of SMA connector. Nevertheless, the achieved bandwidth is sufficient to meet the requirement of the aforementioned applications. The detailed results of the simulation and measurement are further given in Table 2 .

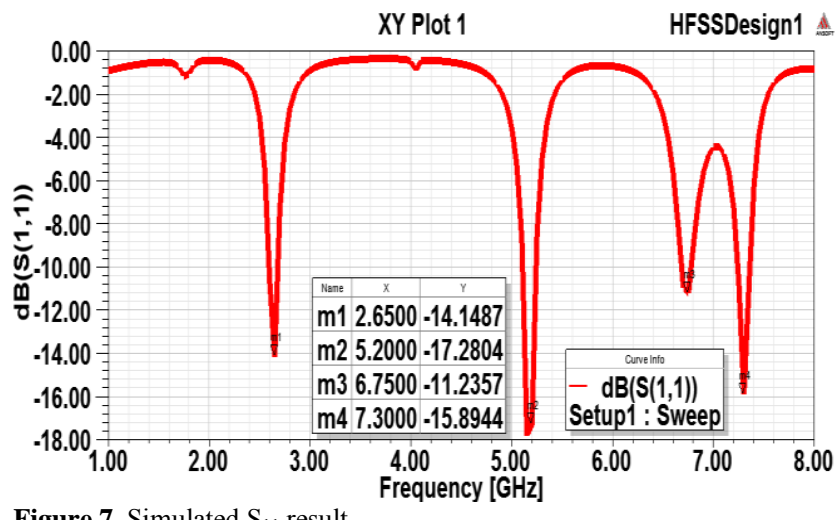

Figure 7. Simulated $\mathrm{S}_{11}$ result 
Trc1 S11 dB Mag 5dB/Ref-10dB Cal int

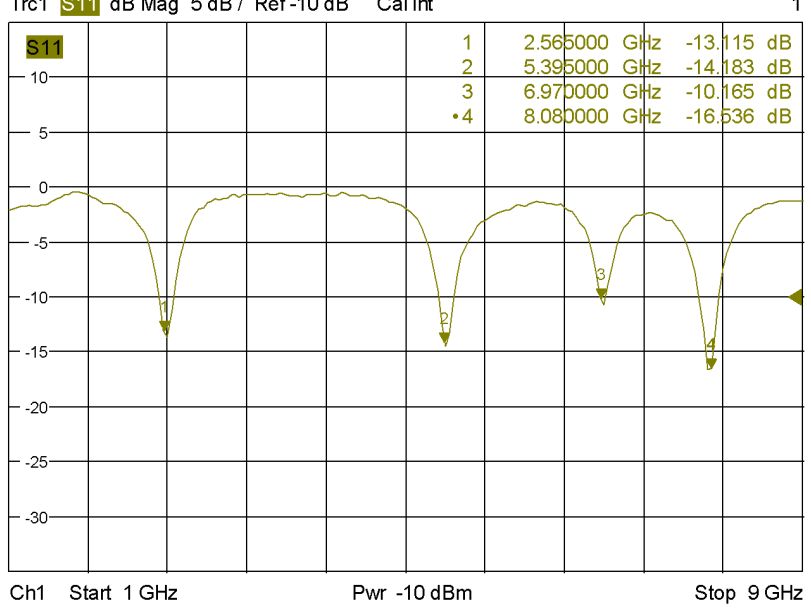

Date: 20.MAR.2018 19:18:23

Figure 8. Measured $\mathrm{S}_{11}$ result

The simulated and measured VSWR of the proposed configuration is illustrated in Figure 9 and 10 respectively. The antenna has VSWR between 1-2 for the entire four band of operation.

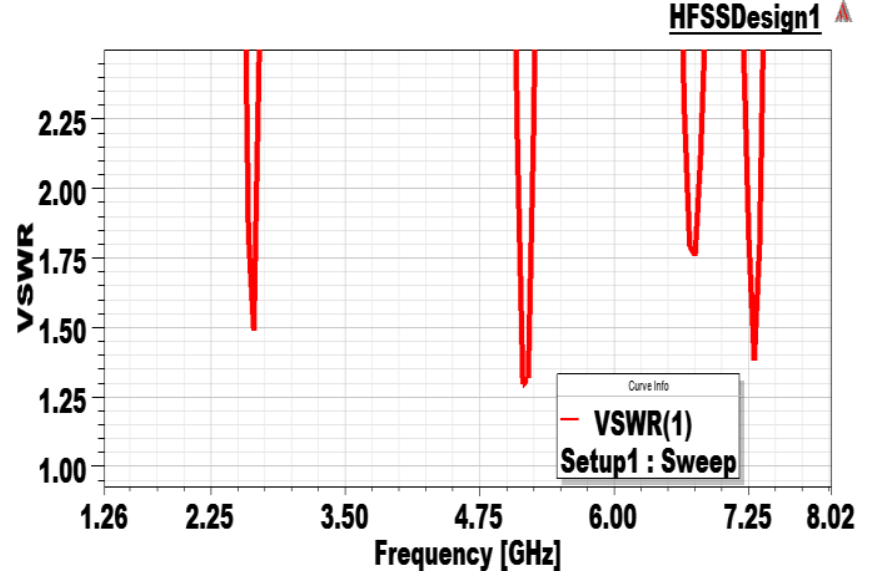

Figure 9. Simulated VSWR of the proposed configuration

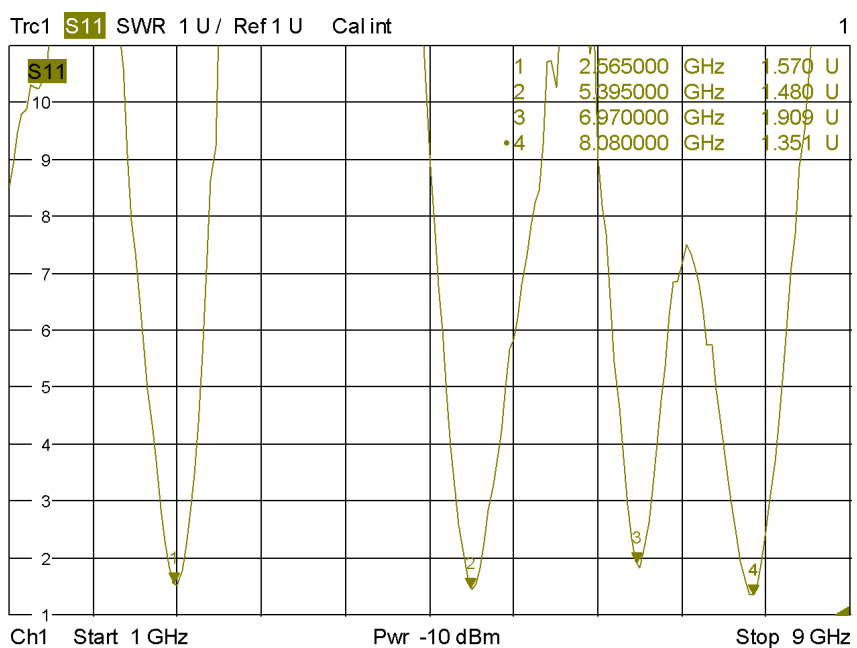

Date: 20.MAR.2018 19:17:23

Figure 10. Measured VSWR of the proposed configuration
Table 2. Compared simulated and measured results

\begin{tabular}{|c|c|l|l|l|l|l|}
\hline Variable & $\begin{array}{l}\text { Freq. } \\
(\mathrm{GHz})\end{array}$ & $\mathbf{S}_{\mathbf{1 1}}$ & $\begin{array}{l}\mathbf{F}_{\mathbf{H}} \\
(\mathrm{GHz})\end{array}$ & $\begin{array}{l}\mathbf{F}_{\mathbf{L}} \\
(\mathrm{GHz})\end{array}$ & $\begin{array}{l}\text { Bandw. } \\
(\mathrm{MHz})\end{array}$ & VSWR \\
\hline \multirow{4}{*}{ Sim. } & 2.65 & -14.15 & 2.68 & 2.6 & 80 & 1.48 \\
\cline { 2 - 7 } & 5.20 & -17.28 & 5.24 & 5.12 & 120 & 1.31 \\
\cline { 2 - 7 } & 6.75 & -11.24 & 6.76 & 6.68 & 80 & 1.75 \\
\cline { 2 - 7 } & 7.30 & -15.89 & 7.36 & 7.26 & 100 & 1.38 \\
\hline \multirow{4}{*}{ Meas. } & 2.56 & -13.11 & 2.64 & 2.48 & 160 & 1.57 \\
\cline { 2 - 7 } & 5.39 & -14.18 & 5.42 & 5.30 & 120 & 1.48 \\
\cline { 2 - 7 } & 6.97 & -10.17 & 7.00 & 6.92 & 80 & 1.90 \\
\cline { 2 - 7 } & 8.08 & -16.54 & 8.12 & 8.04 & 80 & 1.35 \\
\hline
\end{tabular}

The measured polar pattern of the antenna is demonstrated in Figure 11 and 12. The polar pattern is studied for both $\theta=0^{\circ}$ and $\emptyset=90^{\circ}$ condition in both $\mathrm{xz}$ and yz-plane.

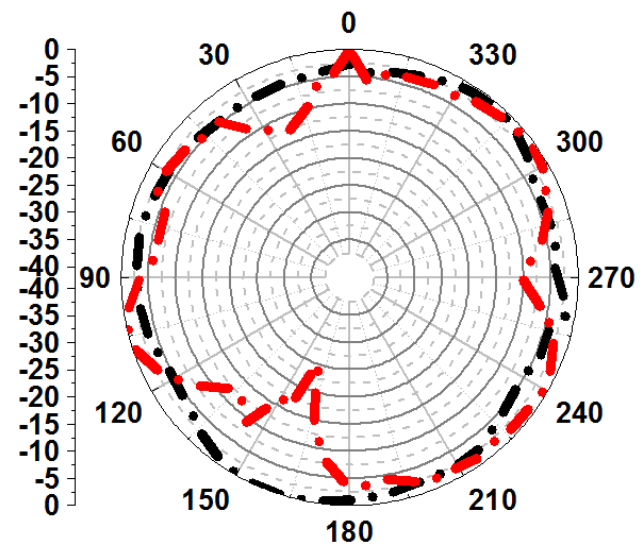

(a)

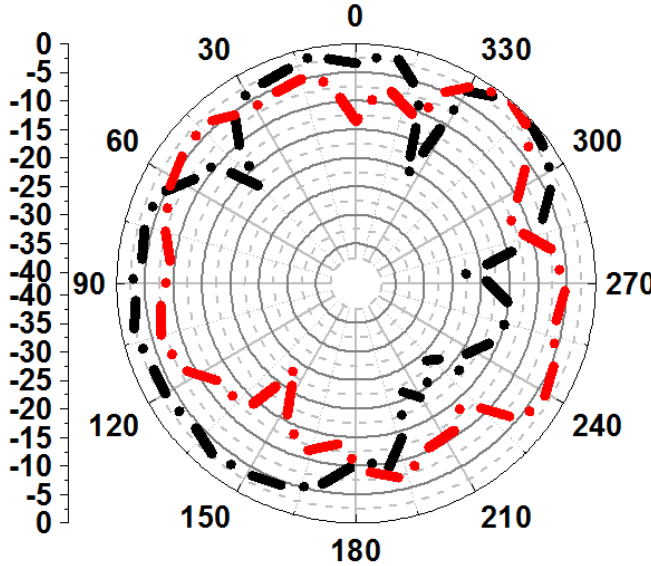

(b)

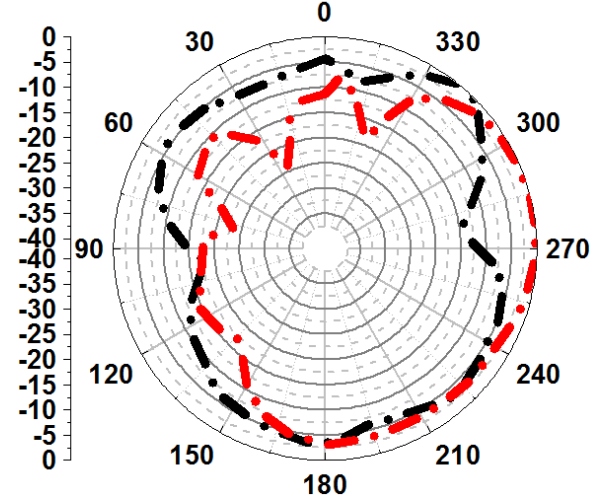

(c) 


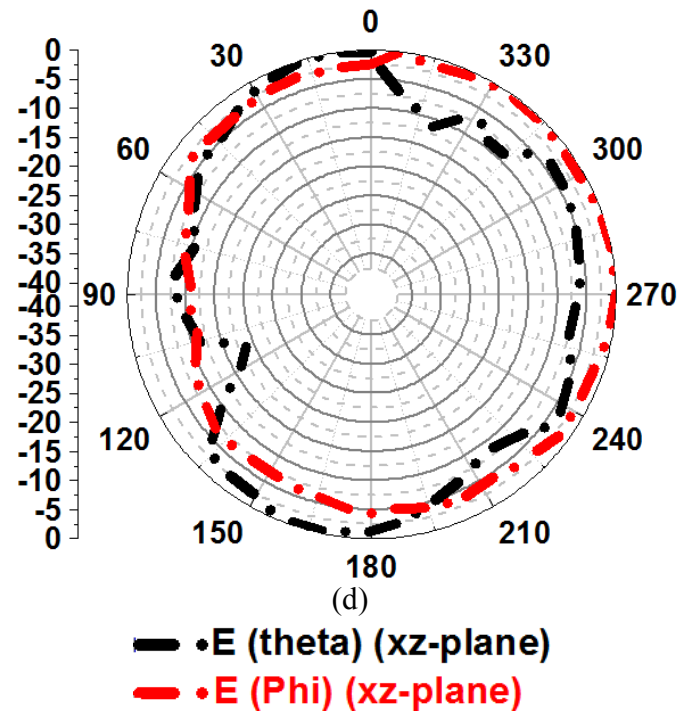

Figure 11. Measured xz-plane normalized radiation pattern for (a) 2.56, (b) 5.39 , (c) 6.97 and (d) $8.08 \mathrm{GHz}$

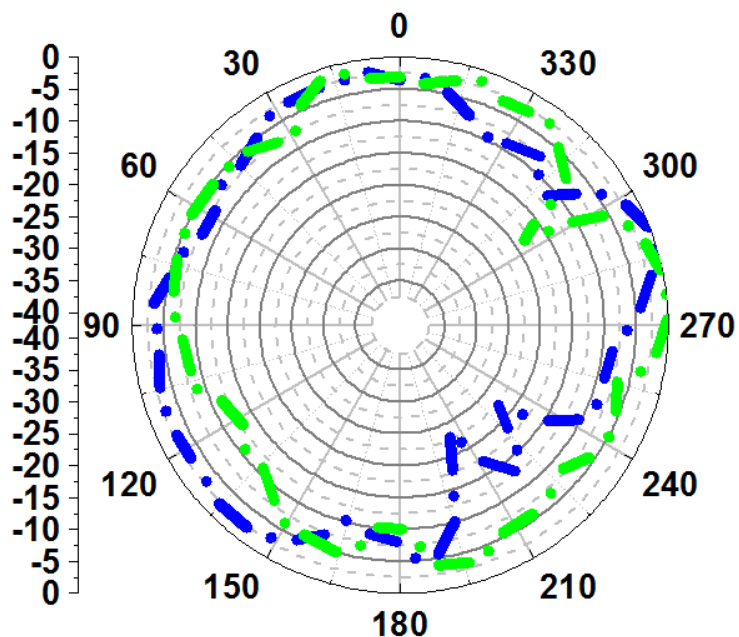

(a)

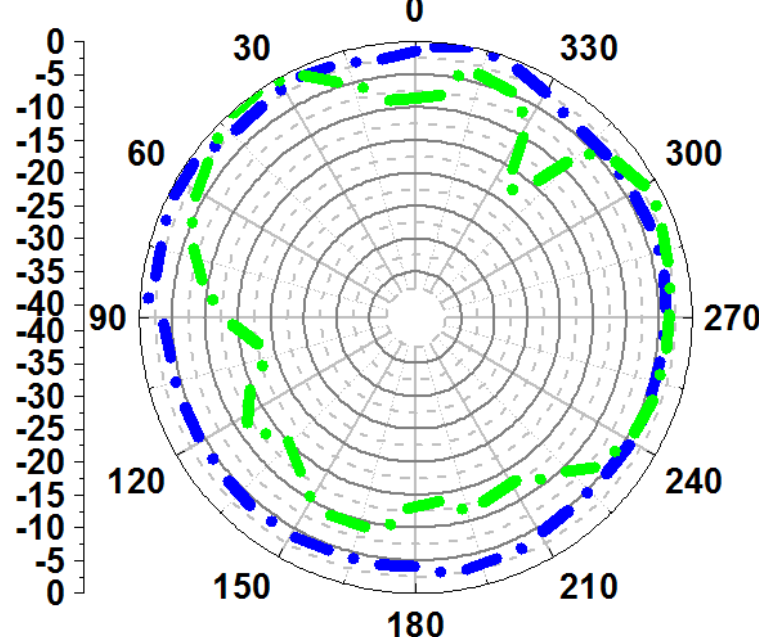

(b)

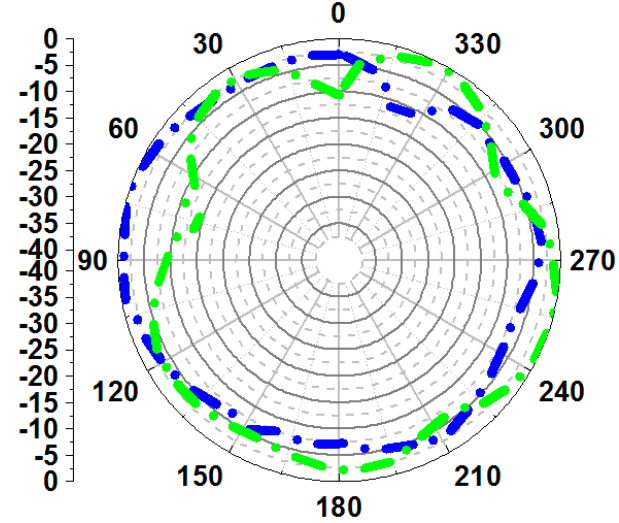

(c)

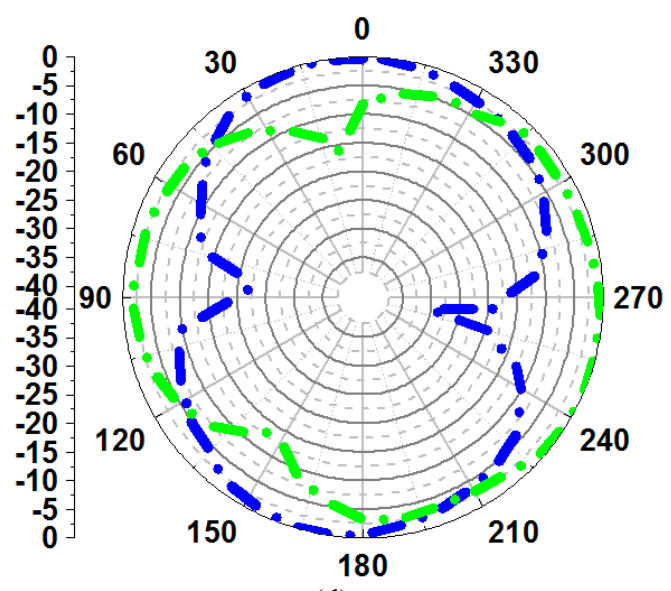

(d)

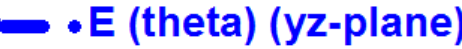

- E (Phi) (yz-plane)

Figure 12. Measured yz-plane normalized radiation pattern for (a) 2.56, (b) 5.39 , (c) 6.97 and (d) $8.08 \mathrm{GHz}$

The radiation efficiency of the proposed configuration is illustrated in Figure 13. The antenna has a radiation efficiency of $33 \%, 53 \%, 69 \%$ and $59 \%$ at the resonant frequencies of $2.65,5.20,6.75$ and $7.30 \mathrm{GHz}$.

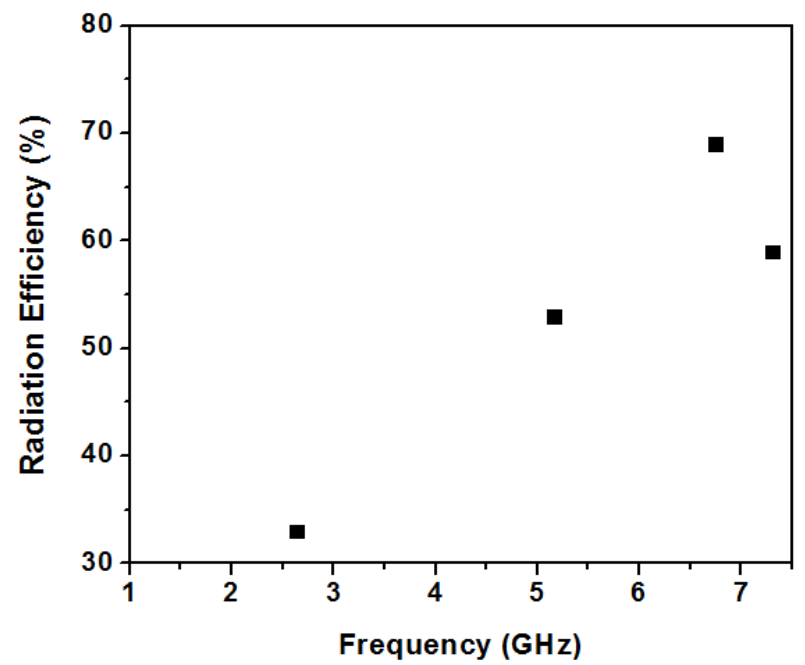

Figure 13. Radiation Efficiency of the proposed configuration 
To know the significance of the proposed design its comparative analysis has been done and is given in Table 3 .

Table 3. Comparision of proposed configuration with others present in literature

\begin{tabular}{|c|c|c|c|c|c|}
\hline Ref. & $\begin{array}{c}\text { size } \\
\left(\mathbf{m m}^{2}\right)\end{array}$ & $\begin{array}{l}\text { No. of } \\
\text { bands }\end{array}$ & $\begin{array}{c}\text { Opert } \\
\text { Freq } \\
(\mathbf{G H z})\end{array}$ & $\begin{array}{c}\text { Bandwidth } \\
(\%)\end{array}$ & $\begin{array}{c}\text { Efficiency } \\
(\%)\end{array}$ \\
\hline \multirow{5}{*}[2]{} & \multirow{5}{*}{$30 \times 24.8$} & \multirow{5}{*}{5} & 2.4 & 6.86 & 33 \\
\hline & & & 2.7 & 5.01 & 43 \\
\hline & & & 4.7 & 9.16 & 84 \\
\hline & & & 5.6 & 5.38 & 72 \\
\hline & & & 8.8 & 5.42 & 75 \\
\hline \multirow{4}{*}{ [16] } & \multirow{4}{*}{$27 \times 29$} & \multirow{4}{*}{4} & 1.5 & 6.06 & \multirow{4}{*}{ NA } \\
\hline & & & 2.4 & 8.33 & \\
\hline & & & 3.5 & 5.55 & \\
\hline & & & 5.2 & 5.94 & \\
\hline & & & 3 & & \\
\hline [17] & $32 \times 40$ & 3 & $\begin{array}{c}5.3 \\
8\end{array}$ & NA & NA \\
\hline \multirow{3}{*}{ [18] } & \multirow{3}{*}{$35 \times 35$} & \multirow{3}{*}{3} & 25 & 4.2 & \\
\hline & & & 3.47 & 2.31 & $\begin{array}{l}00 \\
56\end{array}$ \\
\hline & & & 5.75 & 4.81 & 72 \\
\hline \multirow{4}{*}{ [19] } & \multirow{4}{*}{$28 \times 30$} & \multirow{4}{*}{4} & 1.6 & 3.44 & \multirow[t]{4}{*}{ NA } \\
\hline & & & 2.5 & 7.65 & \\
\hline & & & 5.8 & 8.54 & \\
\hline & & & 9.5 & 3.17 & \\
\hline \multirow{3}{*}{ [20] } & \multirow{3}{*}{$18.4 \times 12$} & \multirow{3}{*}{3} & 6 & 8.47 & \multirow[t]{3}{*}{ NA } \\
\hline & & & 10 & 12.8 & \\
\hline & & & 15 & 6.9 & \\
\hline \multirow{4}{*}{ [21] } & \multirow{4}{*}{$30 \times 30$} & \multirow{4}{*}{4} & 1.5 & 18.07 & 91 \\
\hline & & & 3.5 & 6.89 & 85.5 \\
\hline & & & 5.2 & 5.74 & 87 \\
\hline & & & 5.8 & 5.04 & 86 \\
\hline \multirow{4}{*}{ [22] } & \multirow{4}{*}{$48 \times 18$} & \multirow{4}{*}{4} & 1.57 & 5.6 & 76.8 \\
\hline & & & 2.45 & 5.86 & 80.1 \\
\hline & & & 3.5 & 23 & 96.6 \\
\hline & & & 5.2 & 13.7 & 85.5 \\
\hline \multirow{4}{*}{ Prop. } & \multirow{4}{*}{$20 \times 20$} & \multirow{4}{*}{4} & 2.56 & 6.25 & 33 \\
\hline & & & 5.39 & 2.24 & 53 \\
\hline & & & 6.97 & 1.15 & 69 \\
\hline & & & 8.08 & 1.1 & 59 \\
\hline
\end{tabular}

\section{Conclusions}

A compact multiband planar antenna loaded with rectangular and hook-shaped stubs is presented. The antenna has a tuning range of $8 \%, 12 \%, 8 \%$ and $10 \%$ at $2.65,5.20,6.75,7.30 \mathrm{GHz}$ in simulation and about $16 \%$, $12 \%, 8 \%, 18 \%$ at $2.56,5.39,6.97,8.08 \mathrm{GHz}$ under measurement. The parametric variations show that the slight variation in the optimized dimension affects the operating performance of the antenna drastically. Compact size, good impedance matching, acceptable radiation efficiency and stable radiation pattern makes the proposed configuration an attractive candidate for WiMAX/WLAN/Satellite TV applications.

\section{References}

[1] Ali, T., Khaleeq, M. M., \& Biradar, R. C. (2018). A multiband reconfigurable slot antenna for wireless applications. $A E U$ International Journal of Electronics and Communications, 84, 273-280.

[2] Ali, T., Saadh, A. M., Biradar, R. C., Anguera, J., \& Andújar, A. (2017). A miniaturized metamaterial slot antenna for wireless applications. AEU-International Journal of Electronics and Communications, 82, 368-382.

[3] Shanmuganantham, T., \& Kaushal, D. (2017). Miniaturized Rectangular Slotted Nameplate Antenna Design for Satellite and Radio Determination Applications. ETRI Journal, 39(6), 813-819.

[4] Kumar, S., Vishwakarma, R. K., Kumar, R., Anguera, J., \& Andújar, A. (2017). Slotted Circularly Polarized Microstrip Antenn for RFID Application. RADIOENGINEERING, 26(4), 1025.

[5] Prasad, K. D., Ali, T., \& Biradar, R. C. (2017, May). A compact slotted multiband antenna for L-band and WLAN applications. In Recent Trends in Electronics, Information \& Communication Technology (RTEICT), 2017 2nd IEEE International Conference on (pp. 820-823). IEEE.

[6] Yadav, S., Meena, S., \& Kumawat, B. P. (2018). Design of a Spiral-Shaped Slotted Multiband Antenna. In Optical and Wireless Technologies (pp. 447-454). Springer, Singapore

[7] Fathima, N., Nayana, K. S., Ali, T., \& Biradar, R. C. (2017, May). A miniaturized slotted ground fractal Koch multiband antenna for wireless applications. In Recent Trends in Electronics, Information \& Communication Technology (RTEICT), 2017 2nd IEEE International Conference on (pp. 251-255). IEEE.

[8] Wulandari, I. Y., \& Alaydrus, M. (2017, November). Observation of multiband characteristics of microstrip antenna using defected ground structure. In Broadband Communication, Wireless Sensors and Powering (BCWSP), 2017 International Conference on (pp. 1-4). IEEE.

[9] Ali, T., Mohammad, S. A., \& Biradar, R. C. (2017, May). A novel metamaterial rectangular CSRR with pass band characteristics at 2.95 and $5.23 \mathrm{GHz}$. In Recent Trends in Electronics, Information \& Communication Technology (RTEICT), 2017 2nd IEEE International Conference on (pp. 256-260). IEEE..

[10] Ali, T., \& Biradar, R. (2017). A compact multiband antenna using $\lambda / 4$ rectangular stub loaded with metamaterial for IEEE $802.11 \mathrm{~N}$ and IEEE 802.16 E. Microwave and Optical Technology Letters, 59(5), 1000-1006.

[11] Dhande, A. P., \& Rao, K. C. B. (2018). Significance of Split Ring Resonator to Design Multiband Operation by Coupling with Monopole. International Journal of Applied Engineering Research, 13(1), 647-650.

[12] Chu, H. B., \& Shirai, H. (2018). A Compact Metamaterial Quad-Band Antenna Based on Asymmetric E-CRLH Unit Cells. Progress In Electromagnetics Research, 81, 171-179.

[13] Daniel, R. S., Pandeeswari, R., \& Raghavan, S. (2018). A compact metamaterial loaded monopole antenna with offsetfed microstrip line for wireless applications. $A E U$ International Journal of Electronics and Communications, 83, 88-94.

[14] Ishfaq, M. K., Abd Rahman, T., Chattha, H. T., \& Ur Rehman, M. (2017). Multiband Split-Ring Resonator Based Planar 
Inverted-F Antenna for 5G Applications. International Journal of Antennas and Propagation, 2017.

[15] Fallahpour, M., \& Zoughi, R. (2018). Antenna Miniaturization Techniques: A Review of Topology-and Material-Based Methods. IEEE Antennas and Propagation Magazine, 60(1), 38-50.

[16]Ali, T., Khaleeq, M. M., Pathan, S., \& Biradar, R. C. (2018). A multiband antenna loaded with metamaterial and slots for GPS/WLAN/WiMAX applications. Microwave and Optical Technology Letters, 60(1), 79-85.

[17] Rasool, M., Tahir, N., Ijaz, B., Alimgeer, K. S., \& Khan, M. S. (2017, December). A compact tri band microstrip slotted antenna with defected ground for wireless applications. In Signal Processing and Communication Systems (ICSPCS), 2017 11th International Conference on (pp. 1-4). IEEE.

[18] Ali, T., \& Biradar, R. C. (2018). A triple-band highly miniaturized antenna for WiMAX/WLAN applications. Microwave and Optical Technology Letters, 60(2), 466-471.

[19] Ali, T., Khaleeq, M. M., \& Biradar, R. C. (2018). A multiband reconfigurable slot antenna for wireless applications. $A E U$ International Journal of Electronics and Communications, 84, 273-280.

[20] Ishfaq, M. K., Abd Rahman, T., Chattha, H. T., \& Ur Rehman, M. (2017). Multiband Split-Ring Resonator Based Planar Inverted-F Antenna for 5G Applications. International Journal of Antennas and Propagation, 2017.

[21]Ali, T., \& Biradar, R. C. (2017). A miniaturized volkswagen logo UWB antenna with slotted ground structure and metamaterial for GPS, WiMAX and WLAN applications. Progress In Electromagnetics Research, 72, 2941.

[22] Cao, Y. F., Cheung, S. W., \& Yuk, T. I. (2015). A multiband slot antenna for GPS/WiMAX/WLAN systems. IEEE Transactions on Antennas and Propagation, 63(3), 952-958. 